\section{RAMSAY HUNT SYNDROME}

\section{(Case Report)}

\author{
Gp Capt LK KOCHHAR, vsm ${ }^{*}$, Maj SC GUPTA ${ }^{+}$, \\ Lt Col S KAMARAVELU ${ }^{\#}$
}

MJAFI 1998; 54 : 365-366

KEY WORDS : Facial nerve paralysis; Ramsay Hunt syndrome.

\section{Introduction}

$\mathbf{R}$ amsay Hunt in 1907 [1] described a clinical syndrome comprising of herpes zoster oticus, lower motor facial nerve paralysis with or without deafness, tinnitus and vertigo due to geniculate ganglionitis. Thereafter different clinical variations involving 5 th, 8th, 9th and 10th cranial nerves have also been described as unusual presentation. Aseptic meningitis and encephalitis associated with Ramsay Hunt Syndrome have also been recently described. Very rarely herpes zoster cephalicus with facial nerve palsy affects not only the cochlear and vestibular labyrinth but also the brain stem and several other cranial nerves [2-3] as seen in this presented case which along with Ramsay Hunt syndrome had haemorrhagic infarction in the the internal capsule region which is a rare presentation.

\section{Case Report}

A 72 years old ex-serviceman presented with features of lower motor neuron facial paralysis of left side (Fig. 1). It was of abrupt onset. Alongwith this he also had severe giddiness, hearing loss on left side and weakness of right side of the body. Patient did not give any history of loss of consciousness or fits. On examination patient was found to have vital parameters within normal limits with blood pressure of $130 / 90 \mathrm{mmHg}$. No carotid bruit was heard. ENT examination revealed complete lower motor neuron facial paralysis on left side, severe sensorineural hearing loss in the left ear and spontaneous first degree horizontal nystagmus to right side. Multiple vesicular cruptions were seen in the hollow of the concha, external auditory meatus (Fig. 2), left side soft palate. uvula and left side gum. Central nervous system examination revealed power in right upper limb 4/5. Deep tendon jerks and planters were normal.

Investigation revealed routine blood counts within normal limits. ESR was $48 \mathrm{~mm}$ fall in the first hour. Blood sugar fasting was $82 \mathrm{mg} \%$, post prandial $114 \mathrm{mg} \%$, urea $26 \mathrm{mg} \%$, Lipid profile within normal limits and ECG also within normal limits. Lumbar puncture showed CSF of normal cyology and bio-chemistry.

Pure tone audiometry revealed severe sensorineural hearing loss in the left ear. Caloric tests showed no response on left side.
CT scan showed features of mild cortical atrophy with hacmorrhagic infarction in the left internal capsule (Fig 3)

The patient was managed with physiotherapy and prednisolone $30 \mathrm{mg}$ daily in divided doses initially and tapered off slowly. The patient did not show any significant improvement in facial weakness and hearing loss. Improvement was seen only in giddiness and right side body weakness. The vesicles healed in a week's time without leaving any scar. Subsequent follow up did not reveal any postherpetic neuralgia.

\section{Discussion}

The syndrome of Ramsay Hunt has been reported

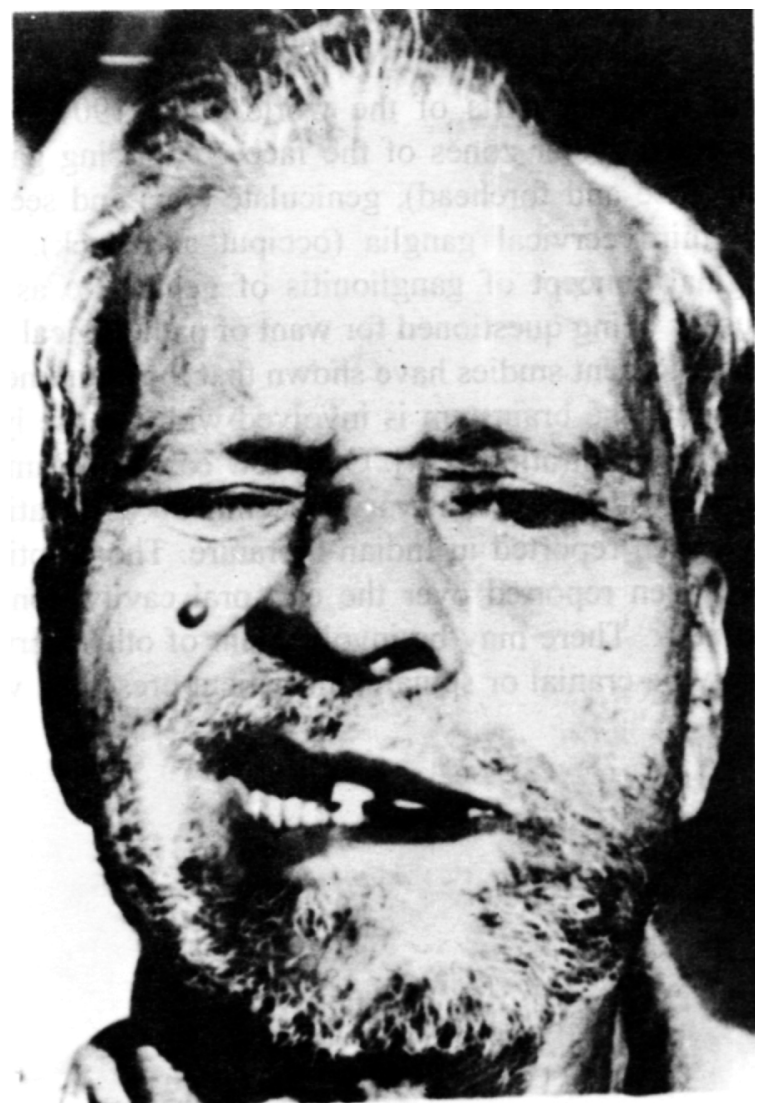

Fig. 1: Photograph shows lower motor neuron facial palsy

\footnotetext{
Senior Advisor and Head of the Department ENT. Army Hospital (R \& R), Delhi Cantt $110010^{+}$Classified Specialist (ENT), ${ }^{\#}$ Classified Specialist (Medicine and Neurology),Command Hospital (EC) Calcutta-27.
} 
366

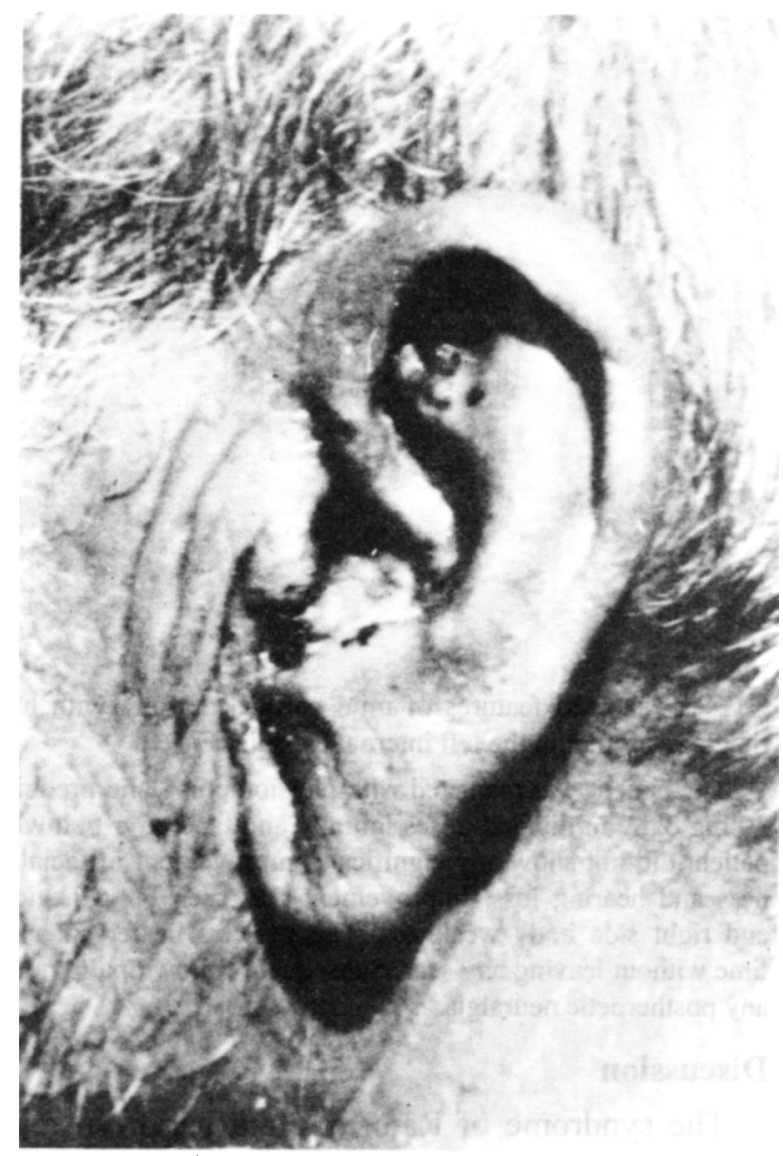

Fig. 2 : Vesicular eruptions over concha and external auditory meatus

from different parts of the world since 1907. Hunt described zoster zones of the face comprising gasserian (face and forehead), geniculate (ear) and second and third cervical ganglia (occiput and neck). The original concept of ganglionitis of geniculate as the cause is being questioned for want of pathological evidence. Recent studies have shown that the entire nerve including the brainstem is involved with intense lymphocytic infiltration [2-4]. Only few cases of Ramsay Hunt Syndrome with varying clinical associations have been reported in Indian literature. The eruptions have been reported over the ear, oral cavity, tonguc and neck. There may be involvement of other nerves, it may be cranial or spinal. Our patient presented with
Kochhar, Gupta and Kumaravelu

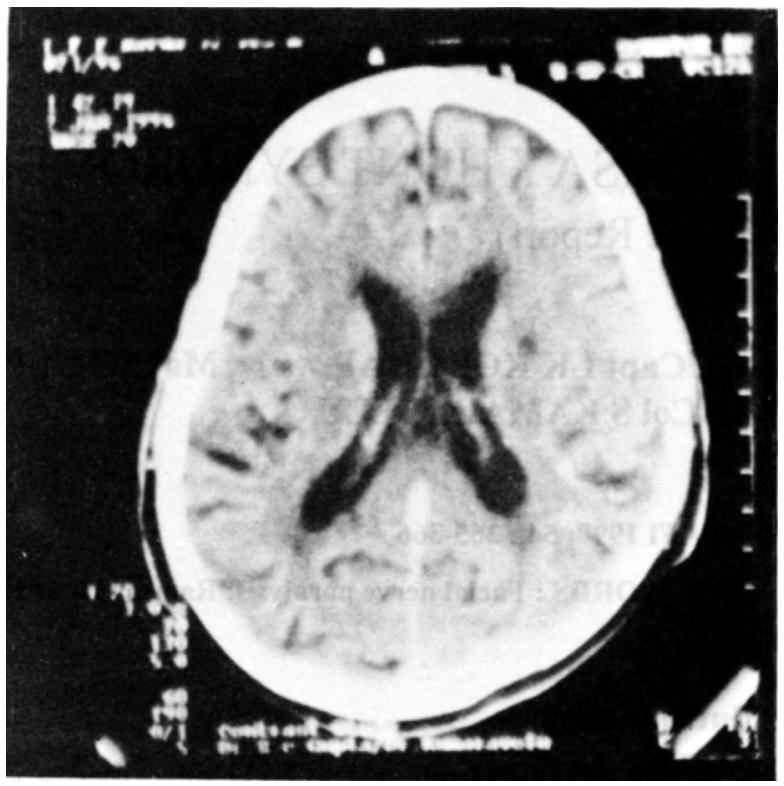

Fig. 3: CT scan showing mild cortical atrophy and haemorrhagic infarction in the internal capsule

acute onset lower motor neuron facial paresis Left with vesicular eruptions over the hollow of concha, external auditory meatus on the left side with ulcers over the left side of palate and gum. He also had left sensori-neural deafness and giddiness suggestive of vestibulo-cochlear impairment. This patient also had right brachial weakness. CT Scan had shown left capsular infarct. Though it may be co-incidental, a possibility of associated intracranial vascular lesion due to zoster infection was entertained.

\section{REFERENCES}

1. Ramsay Hunt. Journal of Mental and Nervous diseases 1907:34,73.

2. Adour KK.Bell's palsy as viral cranial polyganglionitis. In Portman M. (ed), Facial nerve. Masson publishing Inc, New York 1985;PP.233-336.

3. Mori H. Nakai. Bell's palsy and virus: 10 years experience on serological examination. In: Portmann $M$, ed. Facial Nerve. New York. Masson Publishing Inc, 1985: pp-230-3.

4. Harner SG. Heing BA. Newell RC. Herpes zoster oticus. Arch Otol 1970;92:632. 